\title{
Marquardt inverse modeling of the residual gravity anomalies due to simple geometric structures: A case study of chromite deposit
}

\author{
Ata ESHAGHZADEH ${ }^{1, *}$, Alireza DEHGHANPOUR ${ }^{2}$, \\ Sanaz SEYEDI SAHEBARI ${ }^{3}$ \\ ${ }^{1}$ Graduate student of geophysics, Institute of Geophysics, University of Tehran, Iran \\ e-mail: eshagh@alumni.ut.ac.ir, tel: +98936 0161579 \\ ${ }^{2}$ Graduate student of geophysics, Islamic Azad University, Science and Research Branch, \\ Tehran, Iran; e-mail: a.r.dehghanpour@gmail.com, tel: +98 9173054665 \\ ${ }^{3}$ Instructor, Roshdiyeh Higher Education Institute, Tabriz, Iran \\ e-mail: seyedi.sahebari@yahoo.com, +98 9141107646
}

\begin{abstract}
In this paper, an inversion method based on the Marquardt's algorithm is presented to invert the gravity anomaly of the simple geometric shapes. The inversion outputs are the depth and radius parameters. We investigate three different shapes, i.e. the sphere, infinite horizontal cylinder and semi-infinite vertical cylinder for modeling. The proposed method is used for analyzing the gravity anomalies from assumed models with different initial parameters in all cases as the synthetic data are without noise and also corrupted with noise to evaluate the ability of the procedure. We also employ this approach for modeling the gravity anomaly due to a chromite deposit mass, situated east of Sabzevar, Iran. The lowest error between the theoretical anomaly and computed anomaly from inverted parameters, determine the shape of the causative mass. The inversion using different initial models for the theoretical gravity and also for real gravity data yields approximately consistent solutions. According to the interpreted parameters, the best shape that can imagine for the gravity anomaly source is the vertical cylinder with a depth to top of $7.4 \mathrm{~m}$ and a radius of $11.7 \mathrm{~m}$.
\end{abstract}

Key words: chromite deposit, gravity anomaly, Marquardt's algorithm, simple geometric shapes

\section{Introduction}

Non-uniqueness is a feature in the inverse modeling of the residual gravity anomaly as can assign a set of the measured gravity field data on the

\footnotetext{
${ }^{*}$ corresponding author
} 
ground to the geometrical distributions of the subsurface mass with various shapes or physical parameters such as density and depth. One way to eliminate this ambiguity is to put a suitable geometry to the anomalous body with a known density followed by inversion of gravity anomalies (Chakravarthi and Sundararajan, 2004). Although simple models may not be geologically realistic, they are usually are sufficient to analyze sources of many isolated anomalies (Abdelrahman and El-Araby, 1993b). The interpretation of such an anomaly aims essentially to estimate the parameters such as shape, depth, and radius of the gravity anomaly causative body such as geological structures, mineral mass and artificial underground structures.

Several graphical and numerical methods have been developed for analyzing residual gravity anomalies caused by simple bodies, such as Saxov and Nygaard (1953) and Bowin et al. (1986). The methods include, for example, Fourier transform (Odegard and Berg, 1965; Sharma and Geldart, 1968); Mellin transform (Mohan et al., 1986); Walsh transforms techniques (Shaw and Agarwal, 1990); ratio techniques (Hammer, 197r; Abdelrahman et al.,1989); least-squares minimization approaches (Gupta, 1983; Lines and Treitel, 1984; McCowan and Abdelrahman, 1990; Abdelrahman et al., 1991) and different neural networks (Salem et al., 2001; Osman et al., 2006, 2007; Al-Garni, 2013; Eshaghzadeh and Kalantari, 2015; Eshaghzadeh and Hajian, 2018); effective quantitative interpretations using the least-squares method (Gupta, 1983) based on the analytical expression of simple moving average residual gravity anomalies are yet to be developed. Abdelrahman and El-Araby (1993a) introduced an interpretive technique based on fitting simple models convolved with the same moving average filter as applied to the measured gravity. A simple method proposed by Essa (2007) is used to determine the depth and shape factor of simple shapes from residual gravity anomalies along the profile. Another automatic method, the least-squares method, was proposed by Asfahani and Tlas (2008), by which the depth and amplitude coefficient can be determined.

In this paper, a simultaneous non-linear inversion based on Marquardt optimization is developed to estimate the radius and depth parameters of the simple structures such as sphere, infinite horizontal cylinder and semiinfinite vertical cylinder. The Marquardt inversion method has been used for modeling the geological structures such as faulted beds (Chakravarthi and Sundararajan, 2005), anticlinal and synclinal structures (Chakravarthi 
and Sundararajan, 2007, 2008), multiple prismatic structures (Chakravarthi and Sundararajan, 2006). The validity of the method is tested on synthetic gravity data with and without random noise and also on a real gravity data set from Iran.

\section{Gravity of simple geometry}

In gravity, fields of many simple bodies are symmetric about the location of the source. For example, the general gravity $g$ effect caused by simple models (such as a sphere, an infinite horizontal cylinder, and a semi-infinite vertical cylinder as shown in Fig. 1) at point $p\left(x_{i}, z\right)$ is given as (Abdelrahman et al., 1989):

$g\left(x_{i}, z, q\right)=K \frac{z^{m}}{\left(x_{i}^{2}+z^{2}\right)^{q}}$,

where $z$ is the depth, $m=1$ for a sphere or a horizontal cylinder and $m=0$ for a vertical cylinder, $q$, is a value (shape factor) characterizing the nature of the source ( $q=0.5$ for a vertical cylinder, $q=1$ for a horizontal cylinder, and $q=1.5$ for a sphere) and $K$ is an amplitude factor related to the radius $R$ and density contrast $\rho$ of the source, as:

$K= \begin{cases}(4 / 3) \pi G \rho R^{3} & \text { for a sphere, } \\ 2 \pi G \rho R^{2} & \text { for a horizontal cylinder, } \\ \pi G \rho R^{2} & \text { for a vertical cylinder, }\end{cases}$

(a)

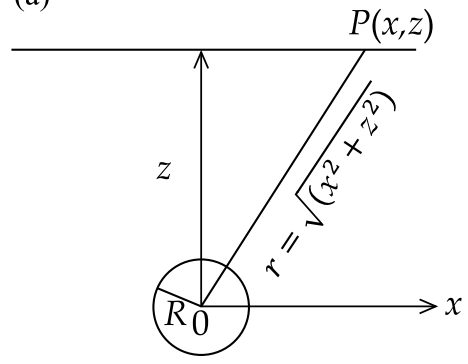

(b)

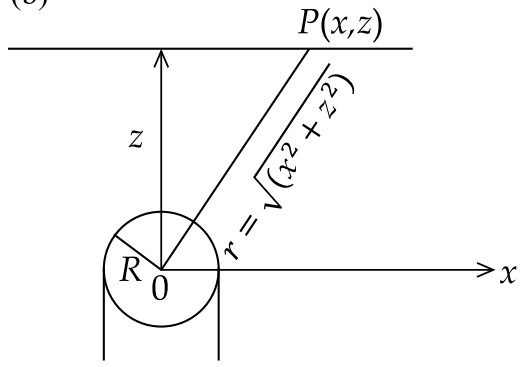

Fig. 1. (a) sphere and infinite horizontal cylinder models, (b) semi-infinite vertical cylinder model. 
where $G$ is the universal gravitational constant. For optimizing the gravity anomaly using Marquardt inversion, the gravity derivatives than the radius (radius derivative) and depth (vertical derivative) must be calculated. The radius and vertical derivative for the sphere model can be computed by equations 3 and 4 , respectively, as:

$\frac{\partial g}{\partial R}=4 \pi G \rho R^{2}\left[\frac{z}{\left(x^{2}+z^{2}\right)^{3 / 2}}\right]$,

$\frac{\partial g}{\partial z}=\frac{4}{3} \pi G \rho R^{3}\left[\frac{x^{2}-2 z^{2}}{\left(x^{2}+z^{2}\right)^{5 / 2}}\right]$,

corresponding expressions for the horizontal cylinder model can be written by:

$\frac{\partial g}{\partial R}=4 \pi G \rho R\left[\frac{z}{\left(x^{2}+z^{2}\right)}\right]$,

$\frac{\partial g}{\partial z}=4 \pi G \rho R^{2}\left[\frac{x^{2}-z^{2}}{\left(x^{2}+z^{2}\right)^{2}}\right]$,

and for the vertical cylinder model the radius and vertical derivatives, respectively, give as following relationship:

$\frac{\partial g}{\partial R}=2 \pi G \rho R\left[\frac{1}{\left(x^{2}+z^{2}\right)^{1 / 2}}\right]$,

$\frac{\partial g}{\partial z}=-\pi G \rho R^{2}\left[\frac{z}{\left(x^{2}+z^{2}\right)^{3 / 2}}\right]$.

\section{Methodology}

The inversion of gravity anomalies is implicitly a mathematical process, trying to fit the computed gravity anomalies to the theoretical ones in the leastsquares approach and then estimating the two parameters namely depth $(z)$ and radius $(R)$. The process of the inversion begins with computing the theoretical gravity anomaly of the simple geometry using equation (1).

The difference between the theoretical gravity $g_{o b s}\left(x_{i}\right)$, and calculated gravity anomaly of an initial assumed model $g_{c a l}\left(x_{i}\right)$, can be estimated by a misfit function, $J$ (Chakravarthi and Sundararajan, 2007), as: 
$J=\sum_{i=1}^{N}\left[g_{o b s}\left(x_{i}\right)-g_{c a l}\left(x_{i}\right)\right]^{2}$,

$N$ is the number of theoretical gravity data. We have employed the Marquardt's algorithm (Marquardt, 1963) given by Chakravarthi and Sundararajan (2006) for minimizing the misfit function until the normal equations can be solved for over all modifications of the two unknowns structural parameters (depth and radius), as:

$$
\begin{array}{r}
\sum_{i=1}^{N} \sum_{k=1}^{2} \frac{\partial g\left(x_{i}\right)}{\partial a_{j}} \frac{\partial g\left(x_{i}\right)}{\partial a_{k}}(1+\delta \lambda) \mathrm{d} a_{k}=\sum_{i=1}^{n}\left[g_{o b s}\left(x_{i}\right)-g_{\text {cal }}\left(x_{i}\right)\right] \frac{\partial g\left(x_{i}\right)}{\partial a_{j}}, \\
\text { for } j=1,2,
\end{array}
$$

where $\mathrm{d} a_{k}, k=1$ and 2 are the amendments to the two model parameters of the simple geometry structure, i.e. depth and radius. Partial derivatives required in the above system of equation (10) are calculated by the equations (3) to (8) according to the shape of the considered model. Also,

$\delta= \begin{cases}1 & \text { for } k=j, \\ 0 & \text { for } k \neq j,\end{cases}$

and $\lambda$ is the damping factor. The advancements, $\mathrm{d} a_{k}, k=1$ and 2 evaluated from equation (10) are then added to or subtracted from the available parameters estimated from last iteration and the process repeats until the misfit, $J$, in equation (9) descends below a predetermined allowable error or the damping factor obtains a large value which is greater than allowable amount or the repetition continues until the end of the considered number for iterations (Chakravarthi and Sundararajan, 2008).

\section{Theoretical examples}

In this section, the performance of the foregoing method are investigated for the gravity anomalies of the three simple geometric models, i.e. sphere, infinite horizontal cylinder and semi-infinite vertical cylinder, with and without added random noise. 


\subsection{Sphere model}

Fig. 2a shows the theoretical and calculated gravity field variations with $1 \mathrm{~m}$ interval along a $100 \mathrm{~m}$ profile due to an initial sphere model with the parameters $z=25 \mathrm{~m}$ and $R=15 \mathrm{~m}$ and an assumed sphere model with parameters $z=30 \mathrm{~m}$ and $R=12 \mathrm{~m}$ (Fig. $2 \mathrm{~b}$ ) where the maximum is the center of the profile. The density contrast is given as $\rho=1000 \mathrm{~kg} / \mathrm{m}^{3}$. Hence, the input initial parameters are $z=30 \mathrm{~m}$ and $R=12 \mathrm{~m}$ which with the theoretical gravity field are exerted to the inversion algorithm coded in Matlab. During inversion, $\rho$ is constant and the model parameters, $z$ and $R$ are improved iteratively. The allowable values for error (misfit, $J$ ), iteration and damping factor $(\lambda)$ are $0.00000001 \mathrm{mGal}, 100$ and 15, respectively. The initial damping factor is 0.5 .

The misfit, $J$, reduces intensely from its initial value of $0.25 \mathrm{mGal}$ at the first iteration to $0.0014 \mathrm{mGal}$ at the end of the 5 th iteration and then gradually reaches $0.000000034 \mathrm{mGal}$ after the 9 th iteration and its value at the 10th iteration becomes $0.00000000014 \mathrm{mGal}$ which is smaller than the

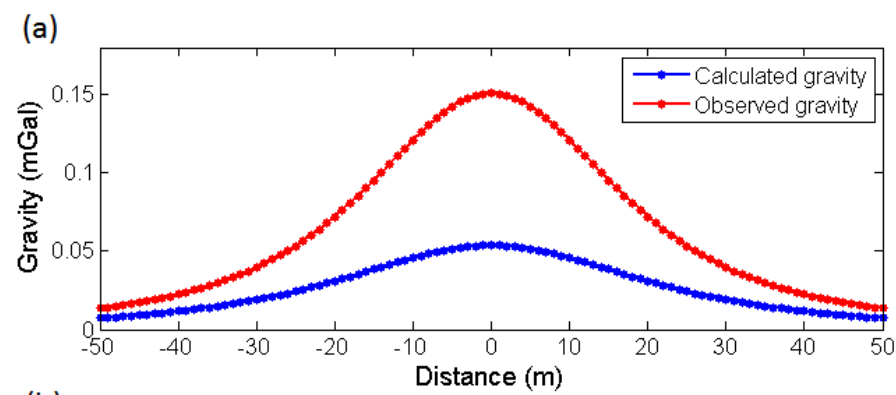

(b)

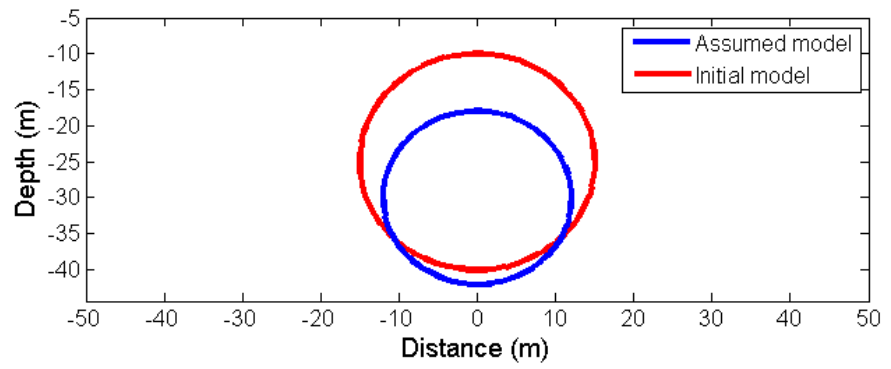

Fig. 2. (a) Theoretical and calculated gravity due to, (b) initial and assumed sphere models. 
allowable error value (Fig. 3c). The iteration terminated at 10th echo and therefore the estimated parameters at 9th iteration are the final results of the inversion.

Fig. $3 \mathrm{a}$ and $3 \mathrm{~b}$ illustrates the variations of the model parameters $z$ and $R$ during inversion with increasing the iteration number. The conclusive obtained parameters values are $z=24.998 \mathrm{~m}$ and $R=15.001$. Fig. 4a shows the computed gravity anomaly from the inferred structure which is shown in Fig. 4b. The error value in the estimation of the model parameters, that is, depth and radius are $0.008 \mathrm{~m}$ and within $0.007 \mathrm{~m}$, respectively.
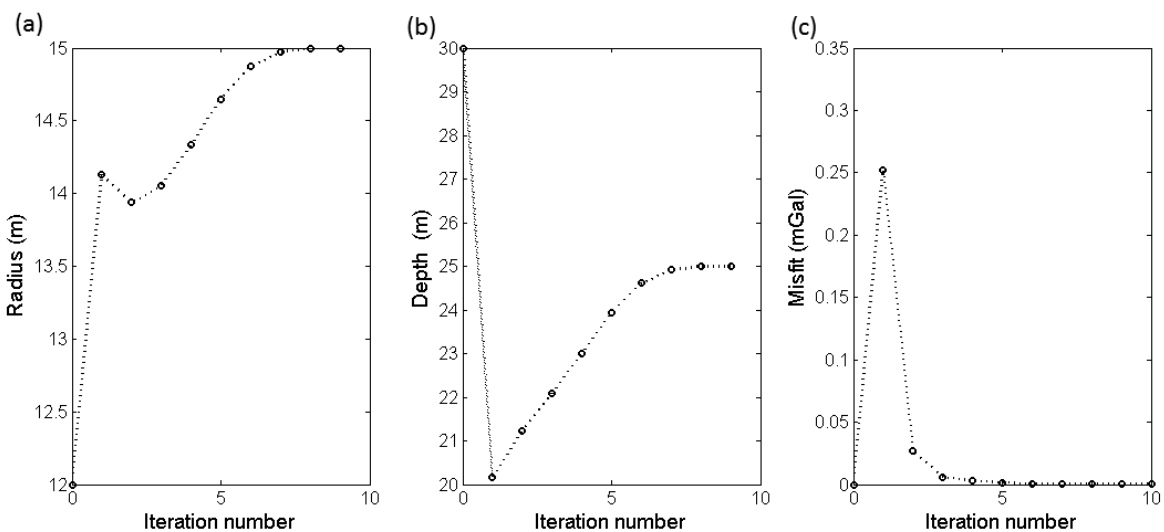

Fig. 3. Improvements of the structures parameters and misfit function versus iteration number for the assumed sphere model in Fig. 2.

The efficacy of error has been evaluated by adding $10 \%$ random noise to the gravity response of the initial sphere model (Fig. 5a) using the following expression:

$g_{\text {nois }}\left(x_{i}\right)=g_{\text {obs }}\left(x_{i}\right)[(1+R N D(i)-0.5) \times 0.1]$,

where $g_{\text {nois }}\left(x_{i}\right)$ is the noise corrupted synthetic data at $x_{i}$, and $R N D(i)$ is a pseudorandom number whose range is between 0 to 1 .

The initial values for the parameters of the assumed sphere model are given as $z=22 \mathrm{~m}$ and $R=12.5 \mathrm{~m}$ (Fig. $5 \mathrm{~b}$ ). The allowable values for error (misfit, $J$ ), iteration and damping factor $(\lambda)$ are $0.00001 \mathrm{mGal}, 100$ and 15 , respectively. The initial damping factor is 0.2 . The misfit, $J$, reduces rapidly from its initial value of $0.061 \mathrm{mGal}$ at the first iteration to $0.00088 \mathrm{mGal}$ 

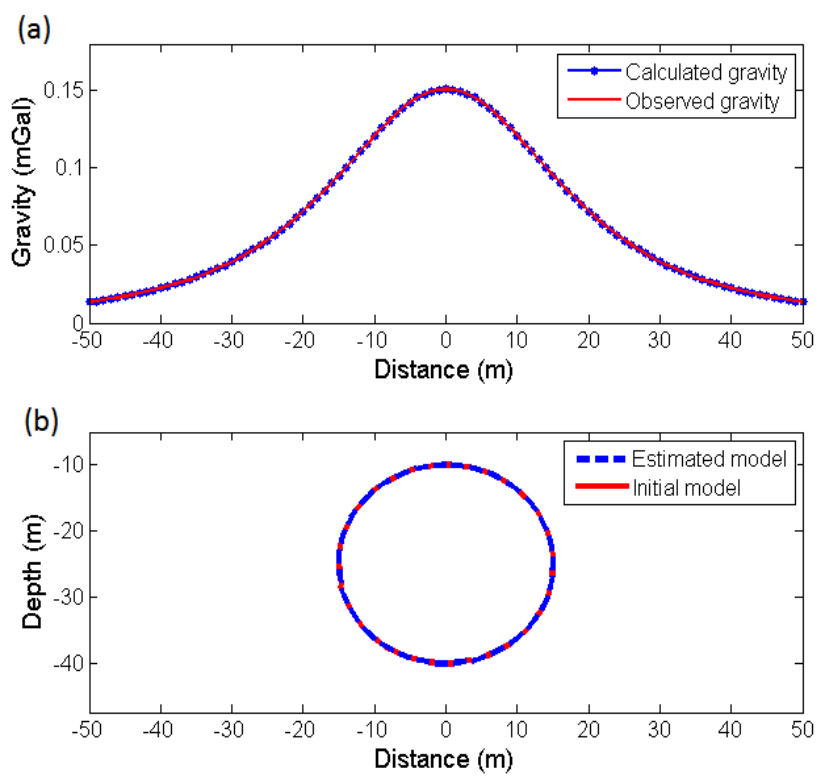

Fig. 4. (a) Theoretical and calculated gravity due to, (b) initial and estimated sphere models.
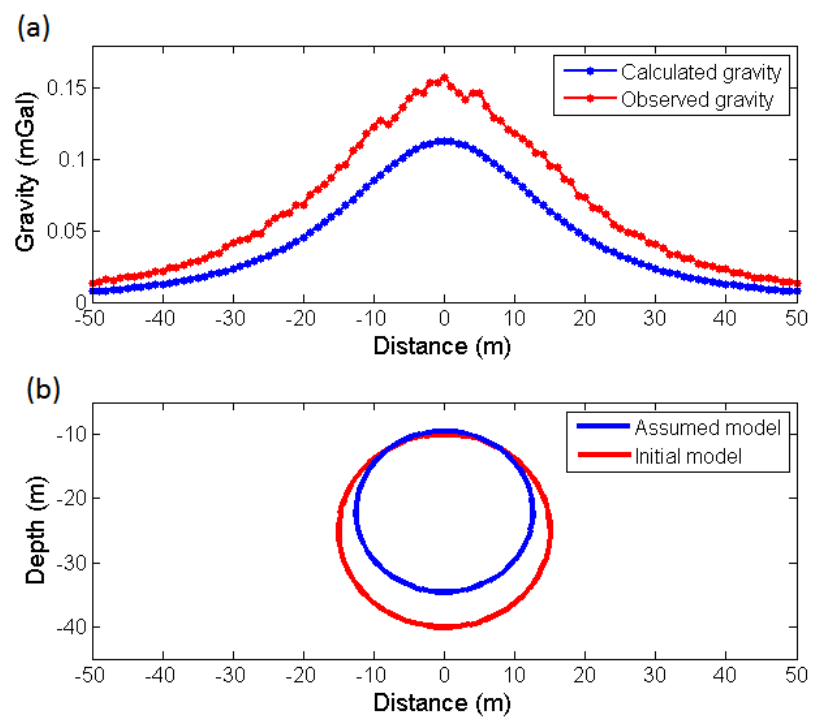

Fig. 5. (a) $10 \%$ noise corrupted theoretical gravity and calculated gravity due to, (b) initial and assumed sphere models. 
at the end of the 6th iteration and then gradually reaches $0.000465 \mathrm{mGal}$ after the 10th iteration and this value remained constant until the last iteration (Fig. 6c). After completing the iteration number, the damping factor, depth and radius attained $0.0000976,24.97 \mathrm{~m}$ and $14.98 \mathrm{~m}$ values, respectively (Fig. 6a and 6b). The amount of error in the estimation of the model parameters, that is, depth and radius are $0.12 \mathrm{~m}$ and within $0.133 \mathrm{~m}$, respectively.
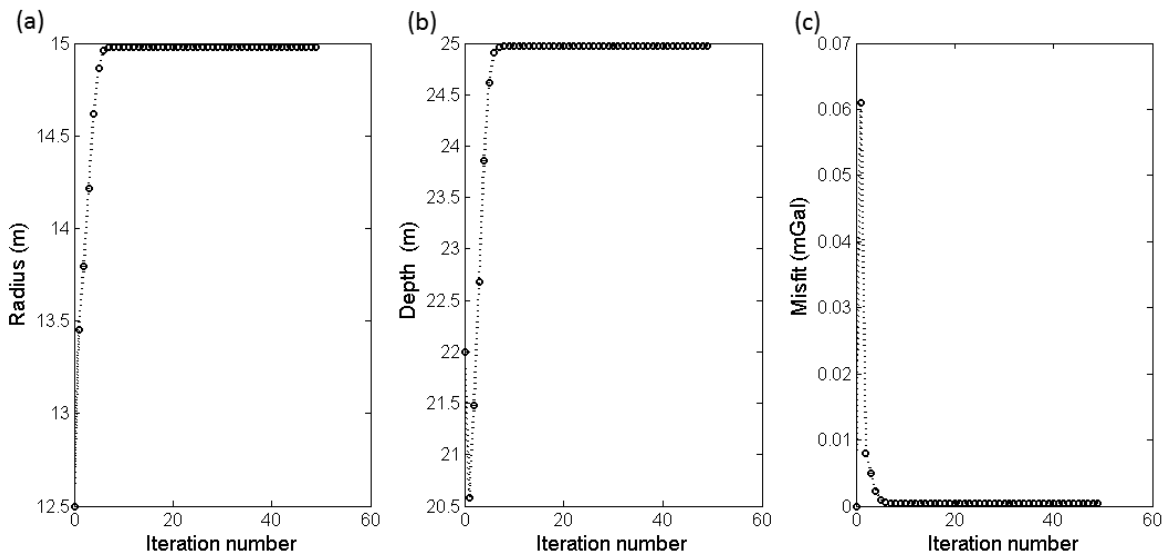

Fig. 6. Improvements of the structures parameters and misfit function versus iteration number for the assumed sphere model in Fig. 5.

Fig. 7a shows the computed gravity anomaly from the inferred structure which is shown in Fig. 7b. The numerical results for the free noise data and contaminated data with the random noise are summarized in Tables 1 and 2 , respectively.

Table 1. Numerical results evaluated from the initial and assumed structural parameters for the each three models.

\begin{tabular}{|c|c|c|c|c|c|c|}
\hline \multirow{2}{*}{ Model } & \multicolumn{2}{|c|}{ Sphere } & \multicolumn{2}{c|}{ Horizontal cylinder } & \multicolumn{2}{c|}{ Vertical cylinder } \\
\hline Parameter & Depth $(\mathrm{m})$ & Radius $(\mathrm{m})$ & Depth $(\mathrm{m})$ & Radius $(\mathrm{m})$ & Depth $(\mathrm{m})$ & Radius $(\mathrm{m})$ \\
\hline Initial & 25 & 15 & 30 & 10 & 30 & 10 \\
\hline Assumed & 30 & 12 & 35 & 7 & 34 & 8 \\
\hline Estimated & 24.998 & 15.001 & 29.999 & 9.997 & 30 & 10 \\
\hline Error \% & 0.008 & 0.007 & 0.003 & 0.03 & 0 & 0 \\
\hline
\end{tabular}


Table 2. Numerical results evaluated from the initial and assumed structural parameters for the each three models after adding $10 \%$ noise to the gravity response of the initial parameters.

\begin{tabular}{|c|c|c|c|c|c|c|}
\hline \multirow{2}{*}{ Model } & \multicolumn{2}{|c|}{ Sphere } & \multicolumn{2}{c|}{ Horizontal cylinder } & \multicolumn{2}{c|}{ Vertical cylinder } \\
\hline Parameter & Depth (m) & Radius (m) & Depth (m) & Radius $(\mathrm{m})$ & Depth (m) & Radius $(\mathrm{m})$ \\
\hline Initial & 25 & 15 & 30 & 10 & 30 & 10 \\
\hline Assumed & 22 & 12.5 & 27 & 12 & 27 & 11.8 \\
\hline Estimated & 24.97 & 14.98 & 30.035 & 9.96 & 29.84 & 9.92 \\
\hline Error \% & 0.12 & 0.133 & 0.12 & 0.4 & 0.53 & 0.8 \\
\hline
\end{tabular}

To test the stability of the Marquardt inversion, two different initial sphere models were assumed to investigate the gravity anomalies related to them with and without a random noise of $10 \%$ (Table 3 and 4). The inferred structural parameters simulate almost the assumed ones.

Table 3. Numerical results evaluated from the various initial and assumed structural parameters for the each three models.

\begin{tabular}{|c|c|c|c|c|c|c|c|c|c|c|c|c|}
\hline Model & \multicolumn{4}{|c|}{ Sphere } & \multicolumn{4}{c|}{ Horizontal cylinder } & \multicolumn{4}{c|}{ Vertical cylinder } \\
\hline Parameter & $\begin{array}{c}\text { Depth } \\
(\mathrm{m})\end{array}$ & $\begin{array}{c}\text { Radius } \\
(\mathrm{m})\end{array}$ & $\begin{array}{c}\text { Depth } \\
(\mathrm{m})\end{array}$ & $\begin{array}{c}\text { Radius } \\
(\mathrm{m})\end{array}$ & $\begin{array}{c}\text { Depth } \\
(\mathrm{m})\end{array}$ & $\begin{array}{c}\text { Radius } \\
(\mathrm{m})\end{array}$ & $\begin{array}{c}\text { Depth } \\
(\mathrm{m})\end{array}$ & $\begin{array}{c}\text { Radius } \\
(\mathrm{m})\end{array}$ & $\begin{array}{c}\text { Depth } \\
(\mathrm{m})\end{array}$ & $\begin{array}{c}\text { Radius } \\
(\mathrm{m})\end{array}$ & $\begin{array}{c}\text { Depth } \\
(\mathrm{m})\end{array}$ & $\begin{array}{c}\text { Radius } \\
(\mathrm{m})\end{array}$ \\
\hline Initial & 35 & 18 & 27 & 10 & 34 & 15 & 27 & 8 & 20 & 15 & 45 & 25 \\
\hline Assumed & 42 & 11 & 19 & 18 & 25 & 10 & 40 & 16 & 13 & 21 & 36 & 30 \\
\hline Estimated & 35 & 18.001 & 26.997 & 10 & 33.998 & 15.002 & 27 & 8.001 & 20 & 15 & 45.003 & 25 \\
\hline Error \% & 0 & 0.006 & 0.01 & 0 & 0.006 & 0.013 & 0 & 0.013 & 0 & 0 & 0.007 & 0 \\
\hline
\end{tabular}

Table 4. Numerical results evaluated from the various initial and assumed structural parameters for the each three models after adding $10 \%$ noise to the gravity response of the initial parameters.

\begin{tabular}{|c|c|c|c|c|c|c|c|c|c|c|c|c|}
\hline Model & \multicolumn{4}{|c|}{ Sphere } & \multicolumn{4}{c|}{ Horizontal cylinder } & \multicolumn{4}{c|}{ Vertical cylinder } \\
\hline Parameter & $\begin{array}{c}\text { Depth } \\
(\mathrm{m})\end{array}$ & $\begin{array}{c}\text { Radius } \\
(\mathrm{m})\end{array}$ & $\begin{array}{c}\text { Depth } \\
(\mathrm{m})\end{array}$ & $\begin{array}{c}\text { Radius } \\
(\mathrm{m})\end{array}$ & $\begin{array}{c}\text { Depth } \\
(\mathrm{m})\end{array}$ & $\begin{array}{c}\text { Radius } \\
(\mathrm{m})\end{array}$ & $\begin{array}{c}\text { Depth } \\
(\mathrm{m})\end{array}$ & $\begin{array}{c}\text { Radius } \\
(\mathrm{m})\end{array}$ & $\begin{array}{c}\text { Depth } \\
(\mathrm{m})\end{array}$ & $\begin{array}{c}\text { Radius } \\
(\mathrm{m})\end{array}$ & $\begin{array}{c}\text { Depth } \\
(\mathrm{m})\end{array}$ & $\begin{array}{c}\text { Radius } \\
(\mathrm{m})\end{array}$ \\
\hline Initial & 35 & 18 & 27 & 10 & 34 & 15 & 27 & 8 & 20 & 15 & 45 & 25 \\
\hline Assumed & 42 & 11 & 19 & 18 & 25 & 10 & 40 & 16 & 13 & 21 & 36 & 30 \\
\hline Estimated & 35.02 & 18.04 & 27.043 & 9.987 & 33.76 & 14.87 & 27.08 & 7.96 & 19.95 & 14.96 & 45.063 & 25.04 \\
\hline Error $\%$ & 0.057 & 0.22 & 0.16 & 0.13 & 0.71 & 0.87 & 0.3 & 0.5 & 0.25 & 0.27 & 0.14 & 0.16 \\
\hline
\end{tabular}


(a)

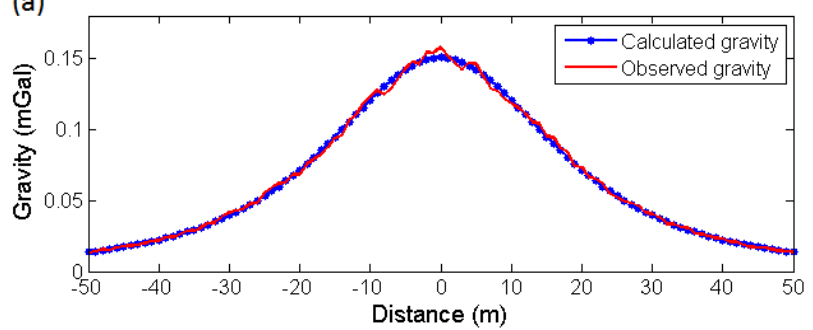

(b)

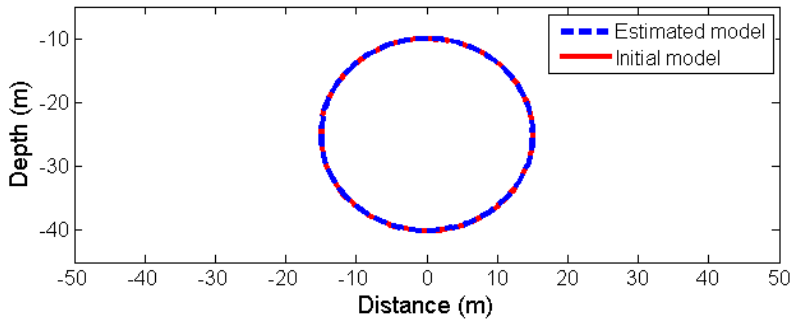

Fig. 7. (a) $10 \%$ noise corrupted theoretical gravity and calculated gravity due to, (b) initial and estimated sphere models.

\subsection{Horizontal cylinder model}

Fig. 8a shows the theoretical and calculated gravity field variations with $1 \mathrm{~m}$ interval along a $100 \mathrm{~m}$ profile due to an initial horizontal cylinder model with the parameters $z=30 \mathrm{~m}$ and $R=10 \mathrm{~m}$ and an assumed horizontal cylinder model with parameters $\mathrm{z}=35 \mathrm{~m}$ and $\mathrm{R}=7 \mathrm{~m}$ (Fig. $8 \mathrm{~b}$ ) where the maximum is the center of the profile and the density contrast is given as $\rho=1000 \mathrm{~kg} / \mathrm{m}^{3}$. Hence, the input initial parameters are $z=35 \mathrm{~m}$ and $R=7 \mathrm{~m}$. During inversion, $\rho$ is constant and the model parameters, $z$ and $R$ are progressed iteratively. The allowable values for error (misfit, $J$ ), iteration and damping factor $(\lambda)$ are $0.00000001 \mathrm{mGal}, 50$ and 12 , respectively. The initial damping factor is 0.5 .

The misfit, $J$, reduces intensely from its initial value of $0.265 \mathrm{mGal}$ at the first iteration to $0.0013 \mathrm{mGal}$ at the end of the 6th iteration and then gradually reaches $0.00000000753 \mathrm{mGal}$ at the 15 th iteration (Fig. 9c). Because the misfit, $J$, obtained a value smaller than the allowable error value at the 15 th echo, the iteration stopped and therefore the depth and radius 
(a)

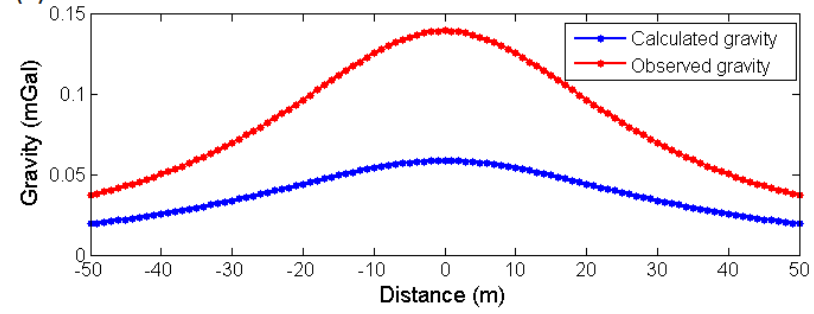

(b)

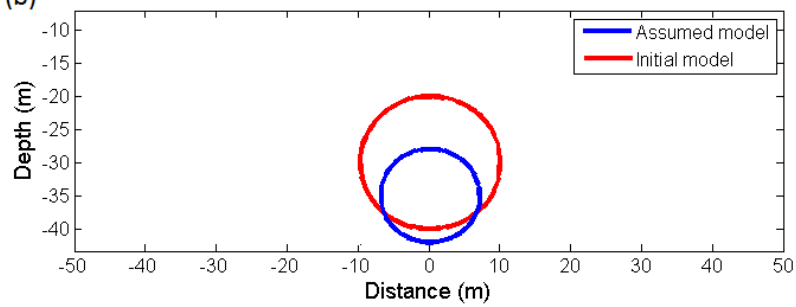

Fig. 8. (a) Theoretical and calculated gravity due to, (b) initial and assumed horizontal cylinder models.

estimates at 14th iteration are the best response of the inverse modeling process.

Fig. 9a and $9 \mathrm{~b}$ shows the variations of the model parameters $z$ and $R$ versus the iteration number. The conclusive obtained parameters values

(a)

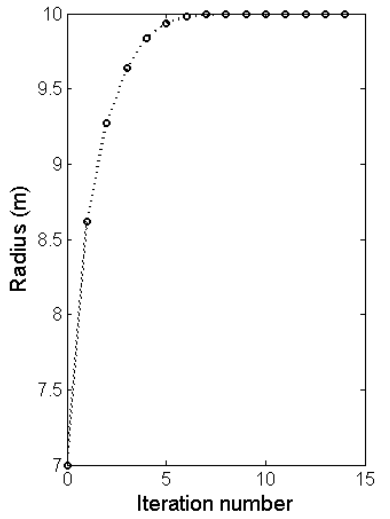

(b)

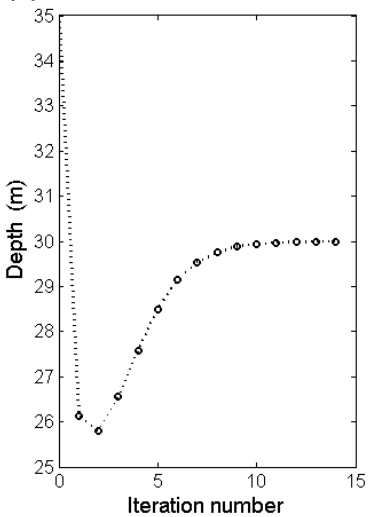

(c)

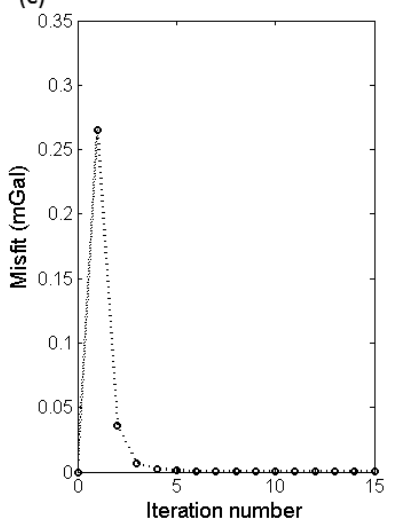

Fig. 9. Improvements of the structures parameters and misfit function versus iteration number for the assumed horizontal cylinder model in Fig. 8. 
are $z=29.999 \mathrm{~m}$ and $R=9.997$. Fig. 10a exhibits the computed gravity anomaly from the resulted model which is shown in Fig. 10b. The error value in the appraisal of the model parameters, that is, depth and radius are $0.003 \mathrm{~m}$ and about $0.03 \mathrm{~m}$, respectively.

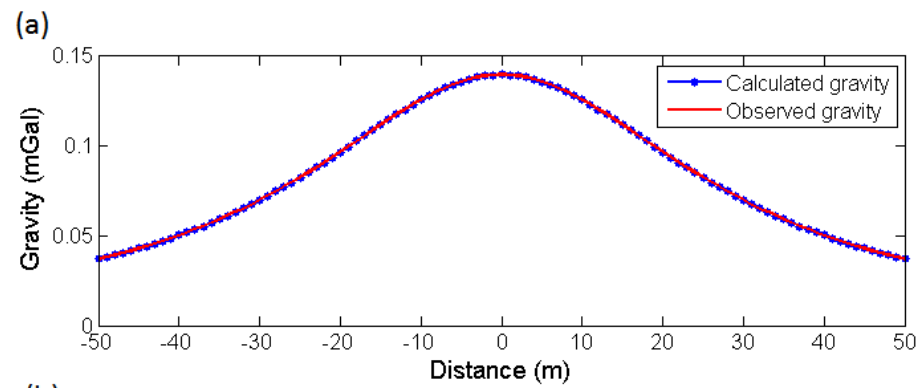

(b)

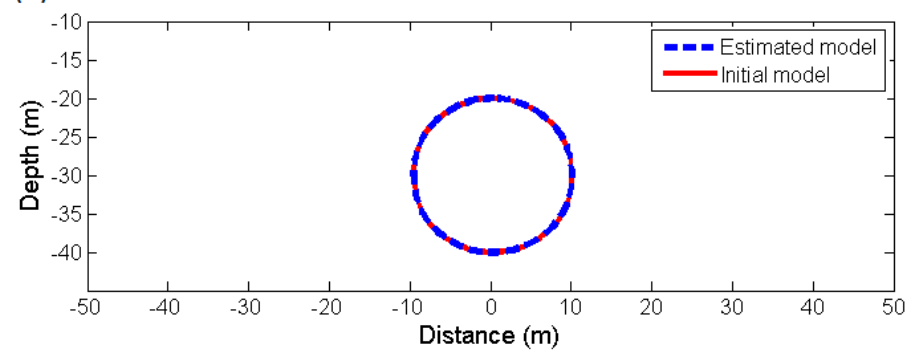

Fig. 10. (a) Theoretical and calculated gravity due to, (b) initial and estimated horizontal cylinder models.

The efficacy of error has been evaluated by adding $10 \%$ random noise to the gravity response of the initial horizontal cylinder model (Fig. 11a) using the equation (11). The initial values for the parameters of the assumed horizontal cylinder model are given as $z=27 \mathrm{~m}$ and $R=12 \mathrm{~m}$ (Fig. 11b). The allowable values for error (misfit, $J$ ), iteration and damping factor $(\lambda)$ are $0.00001 \mathrm{mGal}, 100$ and 15 , respectively. The initial damping factor is 0.2 . The misfit, $J$, reduces quickly from its initial value of $0.247 \mathrm{mGal}$ at the first iteration to $0.0016 \mathrm{mGal}$ at the end of the 4 th iteration and then incrementally attains $0.00074 \mathrm{mGal}$ after the 79 th iteration (Fig. 12c). The iteration finished at the 79th iteration where the damping factor value exceeded from the allowable value. The final values of the evaluated depth and radius are $30.035 \mathrm{~m}$ and $9.96 \mathrm{~m}$, respectively (Fig. 12a,b). The error value in the estimation of the model parameters, that is, depth and radius 
(a)

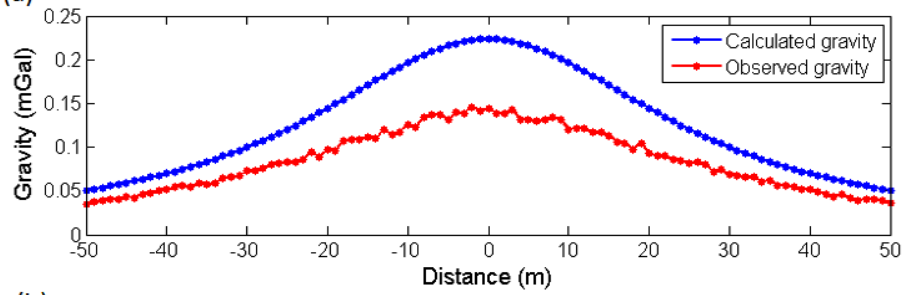

(b)

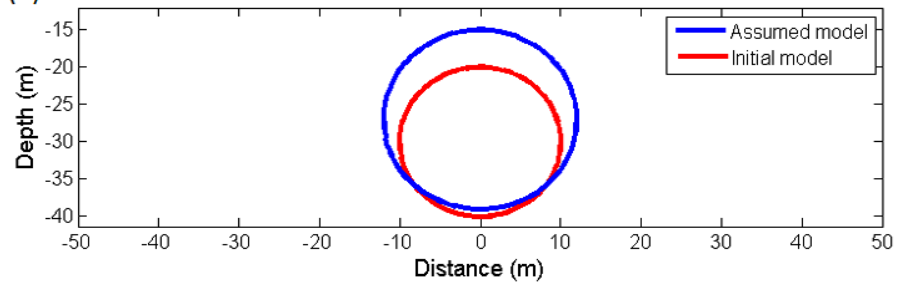

Fig. 11. (a) $10 \%$ noise corrupted theoretical gravity and calculated gravity due to, (b) initial and assumed horizontal cylinder models.

are about $0.12 \mathrm{~m}$ and $0.4 \mathrm{~m}$, respectively.

Fig. 13a shows the generated gravity anomaly of the final structure that is derived from the estimated parameters as shown in Fig. 13b. The numerical results for the gravity data, with and without random noise are tabulated in Tables 2 and 1 , respectively.
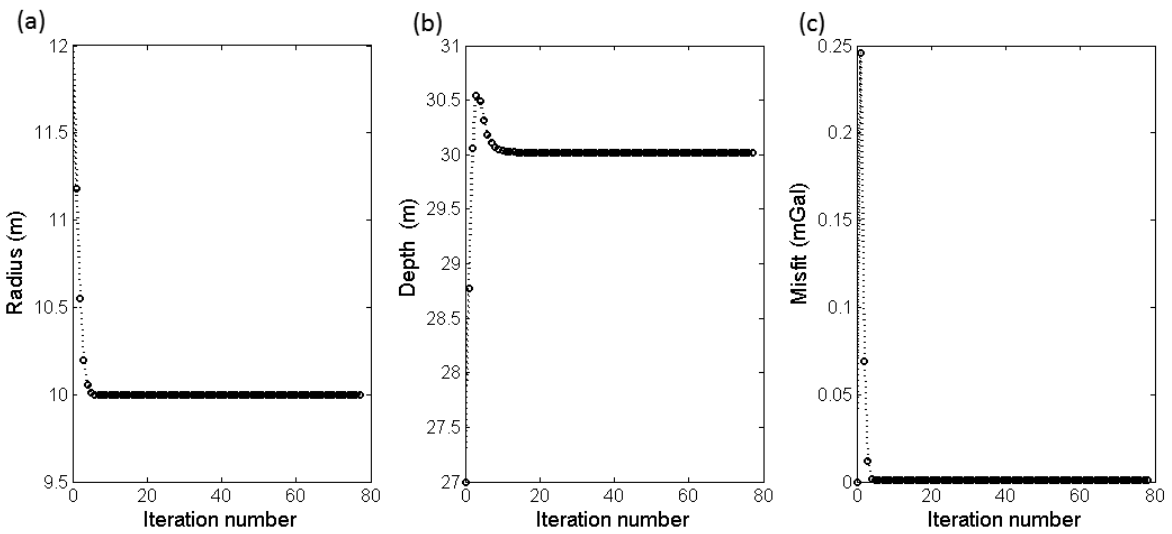

Fig. 12. Improvements of the structures parameters and misfit function versus iteration number for the assumed horizontal cylinder model in Fig. 11. 

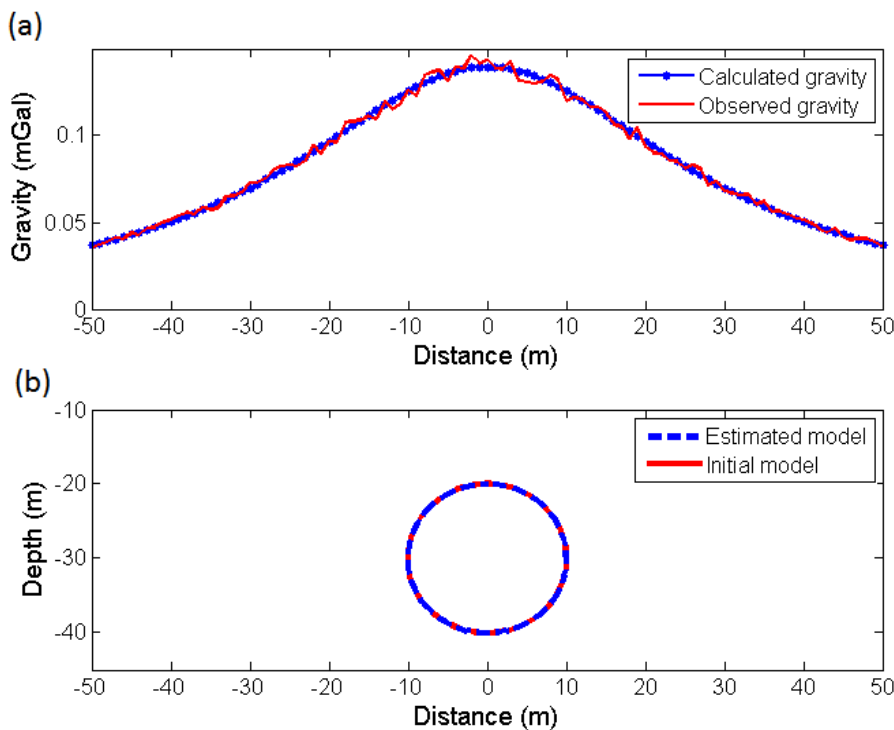

Fig. 13. (a) $10 \%$ noise corrupted theoretical gravity and calculated gravity due to, (b) initial and estimated horizontal cylinder models.

For evaluating the convergence of the Marquardt inversion, two different initial horizontal cylinder models were assumed to consider the gravity anomalies related to them with and without a random noise of $10 \%$ (Table 3 and 4). The estimated structural parameters approximately mimic the supposed ones.

\subsection{Vertical cylinder model}

The theoretical and calculated gravity field variations with $1 \mathrm{~m}$ interval along a $100 \mathrm{~m}$ profile due to an initial infinite vertical cylinder model with the parameters $z=30 \mathrm{~m}$ and $R=10 \mathrm{~m}$ is shows in Fig. 14a and an assumed infinite vertical cylinder model with parameters $z=34 \mathrm{~m}$ and $R=8 \mathrm{~m}$ is shown in Fig. 14b, as the maximum is the center of the profile and the density contrast is given as $\rho=1000 \mathrm{~kg} / \mathrm{m}^{3}$. Hence, the input initial parameters are $z=34 \mathrm{~m}$ and $R=8 \mathrm{~m}$. During inversion, $\rho$ is fixed and the model parameters, $z$ and $R$ are amended iteratively. The allowable values for error (misfit, $J$ ), iteration and damping factor $(\lambda)$ are $0.0000000001 \mathrm{mGal}, 50$ and 15 , respectively. The initial damping factor is 0.5 . 


\section{(a)}

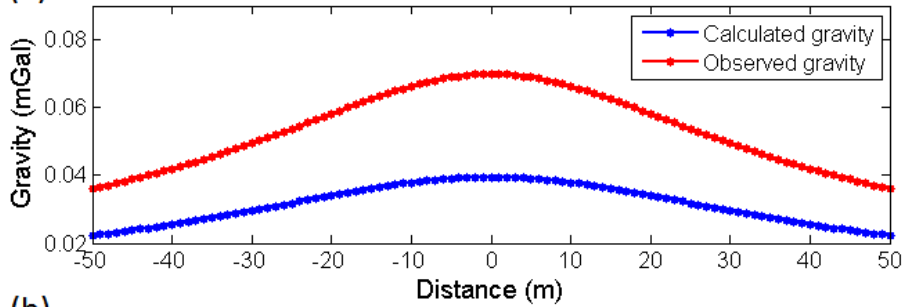

(b)

Distance $(\mathrm{m})$

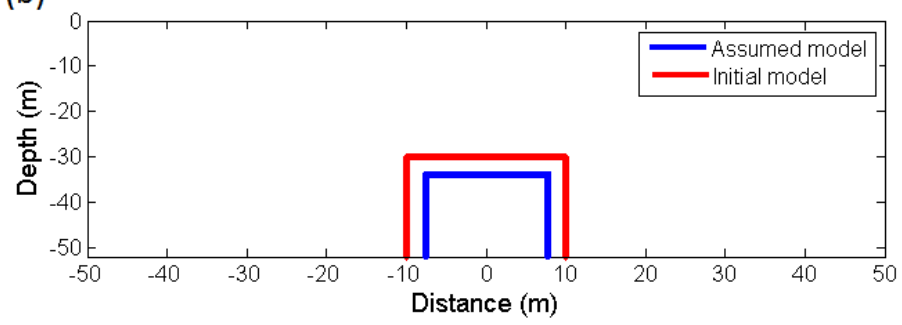

Fig. 14. (a) Theoretical and calculated gravity due to, (b) initial and assumed vertical cylinder models.

The misfit, $J$, decreases intensely from its initial value of $0.053 \mathrm{mGal}$ at the first iteration to $0.00064 \mathrm{mGal}$ at the end of the 5th iteration and then gradually reaches $0.000000000675 \mathrm{mGal}$ at the 9 th iteration and finally attains zero at the end of 10th iteration (Fig. 15c). The depth and radius estimates at 9 th iteration are the final evaluated results.

(a)

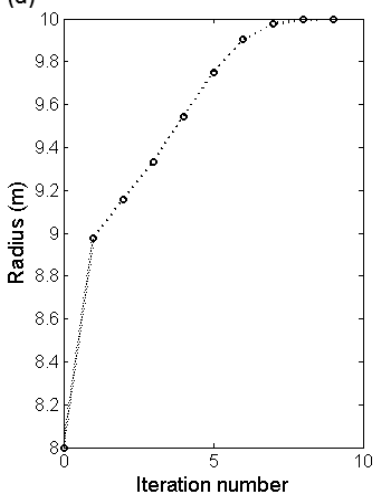

(b)

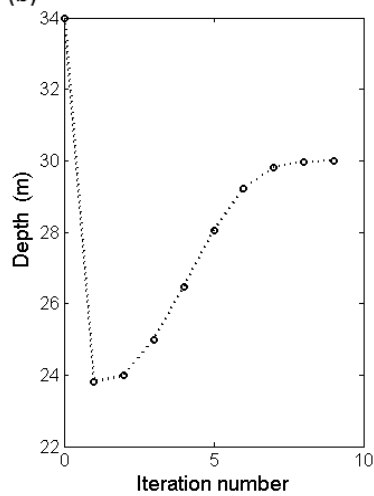

(c)

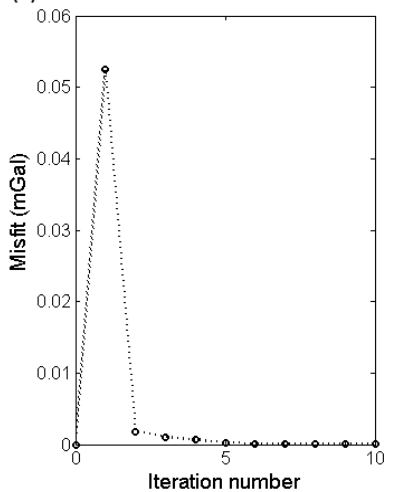

Fig. 15. Improvements of the structures parameters and misfit function versus iteration number for the assumed vertical cylinder model in Fig. 14. 
Fig. 15a,b shows the variations of the model parameters $z$ and $R$ versus the iteration number. The values of the final obtained parameters are $z=$ $30 \mathrm{~m}$ and $R=10$. Fig. 16a displays the calculated gravity anomaly from the resulted model which is shown in Fig. 16b.
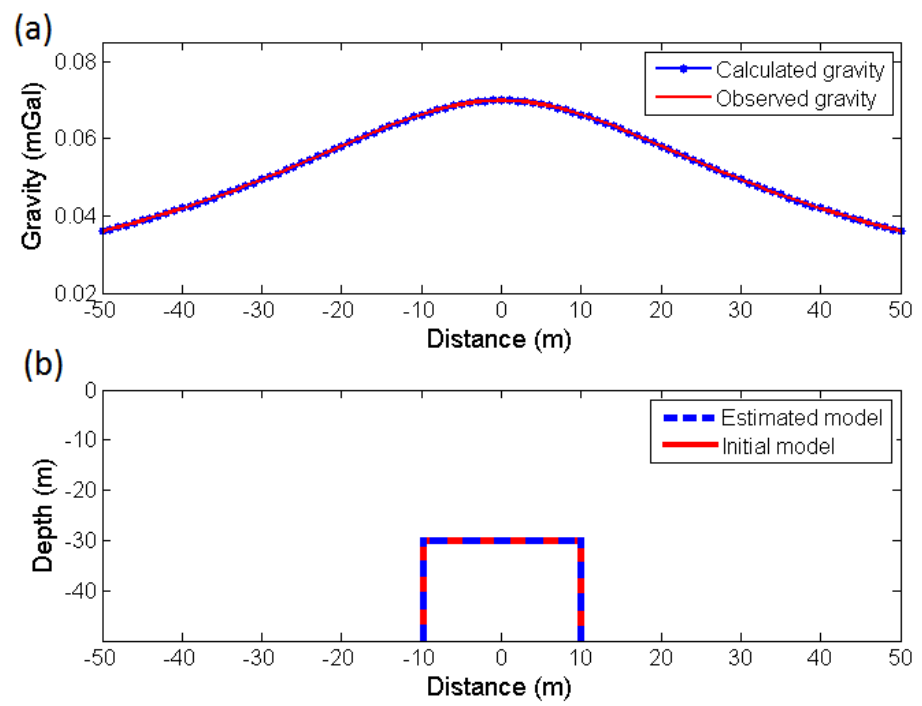

Fig. 16. (a) Theoretical and calculated gravity due to, (b) initial and estimated vertical cylinder models.

The efficiency of the Marquardt inversion method has been investigated by adding $10 \%$ random noise to the gravity response of the initial infinite vertical cylinder model (Fig. 17a) using the equation (11). The initial values for the parameters of the assumed vertical cylinder model are given as $z=$ $27 \mathrm{~m}$ and $R=11.8 \mathrm{~m}$ (Fig. 17b). The allowable values for error (misfit, $J$ ), iteration and damping factor $(\lambda)$ are $0.0001 \mathrm{mGal}, 50$ and 12 , respectively. The initial damping factor is 0.2 . The misfit, $J$, abates sharply from its initial value of $0.075 \mathrm{mGal}$ at the first iteration to $0.00063 \mathrm{mGal}$ at the end of the 4 th iteration and then progressively attains $0.000241 \mathrm{mGal}$ after the 9th iteration as this value remained constant until the iteration number finished (Fig. 18c). The final values of the evaluated depth and radius are $29.84 \mathrm{~m}$ and $9.92 \mathrm{~m}$, respectively (Fig. 18a,b). The amount of error in the estimation of the model parameters, that is, depth and radius are about $0.53 \mathrm{~m}$ and $0.8 \mathrm{~m}$, respectively. 


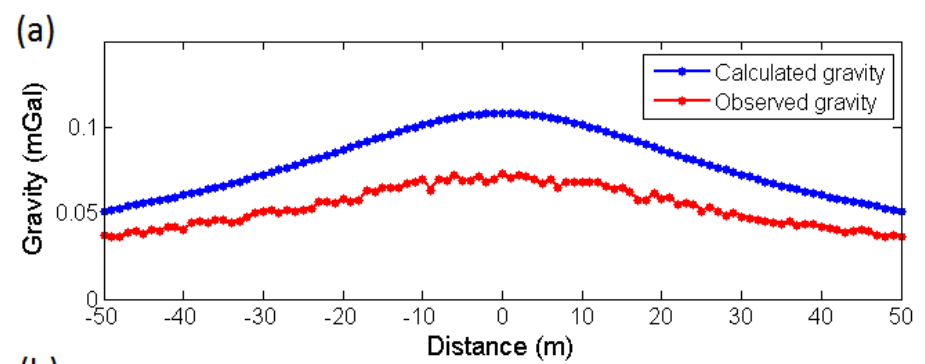

(b)

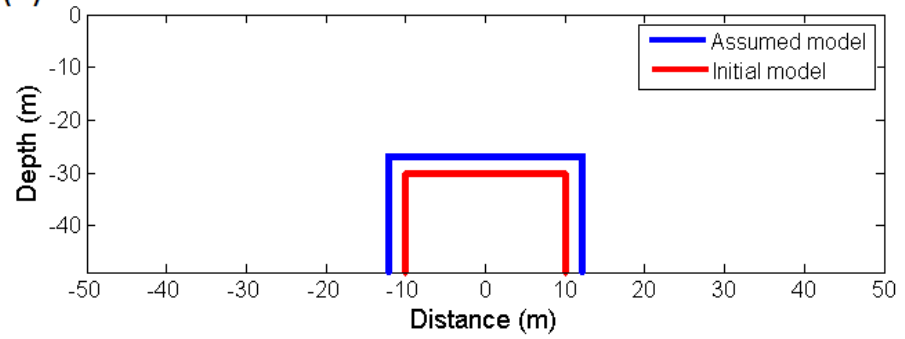

Fig. 17. (a) $10 \%$ noise corrupted theoretical gravity and calculated gravity due to, (b) initial and assumed vertical cylinder models.

(a)

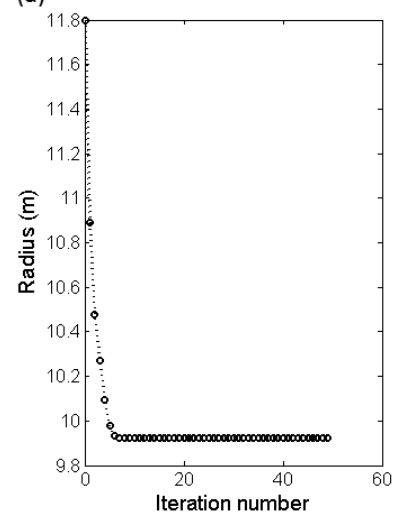

(b)

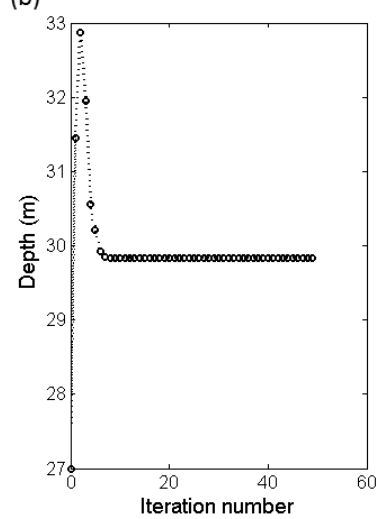

(c)

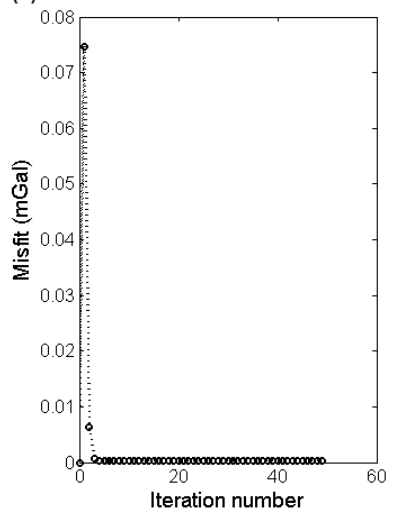

Fig. 18. Improvements of the structures parameters and misfit function versus iteration number for the assumed vertical cylinder model in Fig. 17.

Fig. 19a shows the generated gravity anomaly of the final structure which is inferred from the estimated parameters as shown in Fig. 19b. The numerical results of the gravity data analysis, with and without random noise are given in Tables 2 and 1 , respectively. 
(a)

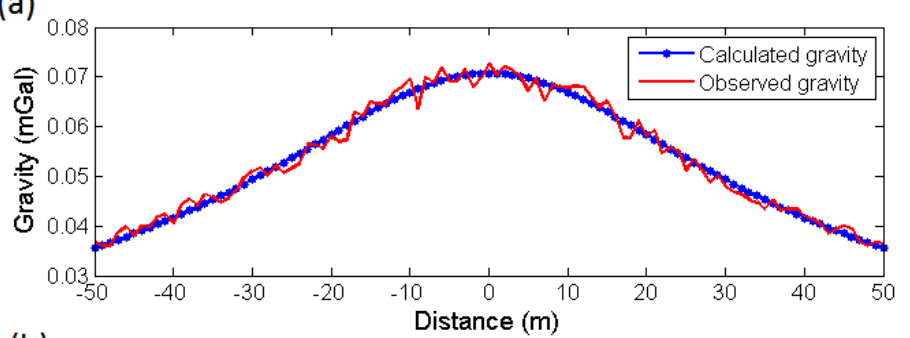

(b)

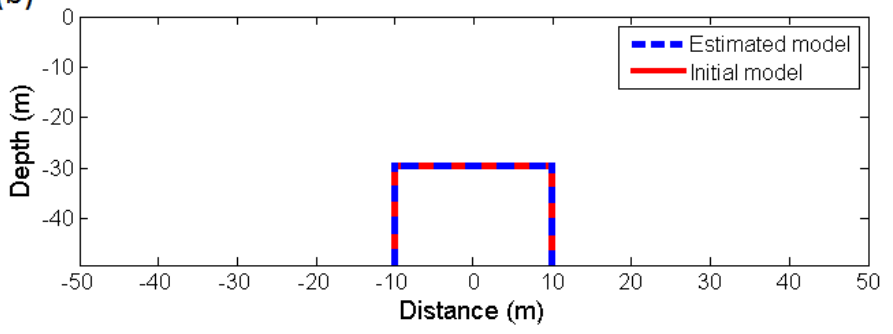

Fig. 19. (a) $10 \%$ noise corrupted theoretical gravity and calculated gravity due to, (b) initial and estimated vertical cylinder models.

To examine the constancy and efficiency of the Marquardt inversion, two different initial vertical cylinder models were presumed to analyze the gravity anomalies related to them with and without a random noise of $10 \%$ (Table 3 and 4). The estimated structural parameters are almost corresponding to the assumed ones.

\section{Field example}

The site under survey is located in the east of Iran, around Sabzevar. The outcomes of the stones in the this area are mostly the alkali and ultrabasic igneous rocks and ophiolite as the chromite mineralization can be found in these rocks (Fig. 20).

In this region, the chromite deposits are massive. Fig. 21 shows the Bouguer gravity anomalies map of the area under consideration. It is worth mentioning, the average density computed by the Nettleton's graphical method for this area is given as $2.8 \mathrm{gr} / \mathrm{cm}^{3}$. The value obtained for the density has been considered for the Bouguer correction. The gravity measurement was done along 12 profiles with a station interval of about $10 \mathrm{~m}$. 


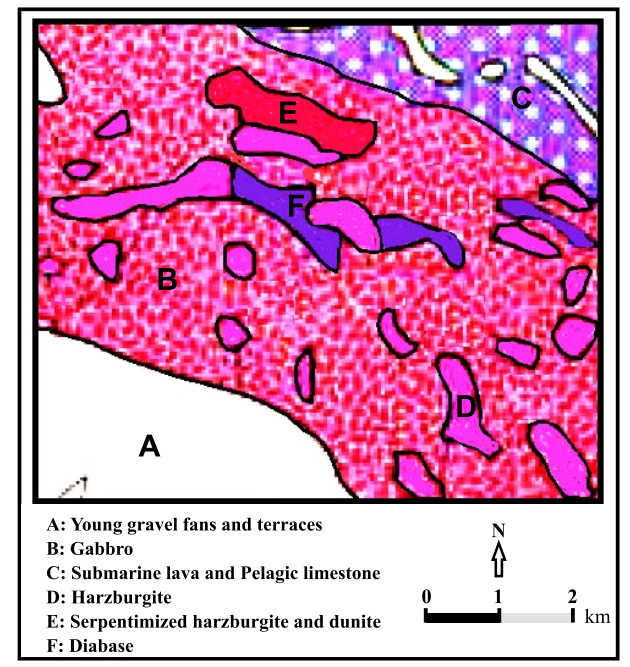

Fig. 20. The geological map of the region under investigation adapted from the Sabzevar 1/250000 geological map (Geological Survey \& Mineral Explorations of Iran - GSI, 2019).

The gravity data covering a $120 \times 100 \mathrm{~m}$ area of the Sabzevar region.

For reaching to the residual gravity anomalies which is our desire, the regional gravity anomalies must be removed using a trend (degree 2) from the Bouguer anomaly. Fig. 22 displays the map of the computed local grav-
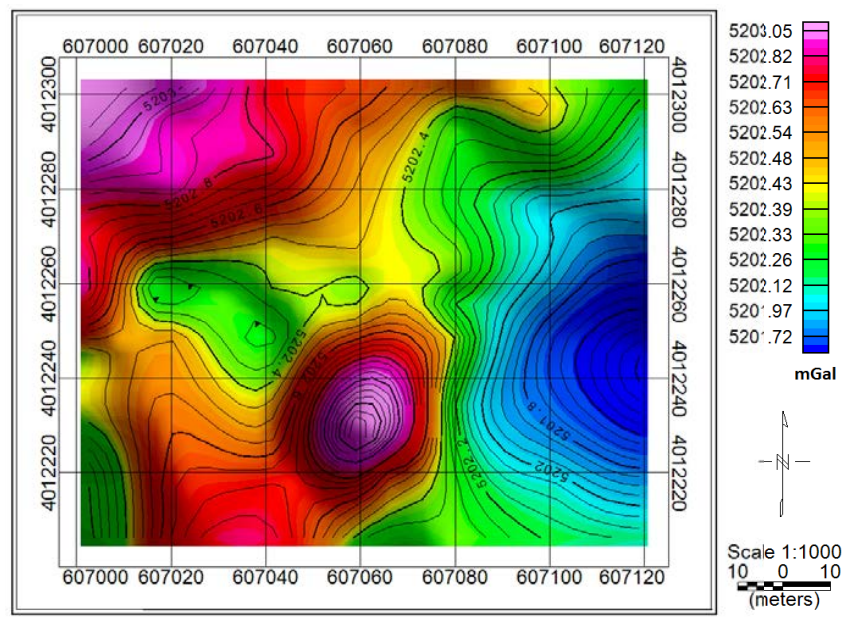

Fig. 21. The Bouguer gravity anomalies map of the area under consideration. 
ity field. The host rock of the chromite have the positive density contrast than the surrounding formation, therefore on the residual gravity anomalies map is appeared as the positive anomaly. The average density of the chromite mass is about $4.5 \mathrm{gr} / \mathrm{cm}^{3}$, whereas the density of the encompassing formation is between $3 \mathrm{gr} / \mathrm{cm}^{3}$ to $3.5 \mathrm{gr} / \mathrm{cm}^{3}$. The positive gravity anomaly related to the chromite deposit has been outlined with gray in Fig. 22. Here, we analyze the residual gravity field variations along the profile $A A^{\prime}$ which runs across the chromite mineral mass in a approximately $\mathrm{W}-\mathrm{E}$ direction as is shown in Fig. 22. The length of profile is $42 \mathrm{~m}$ and the gravity sampling interval is given as $2 \mathrm{~m}$.

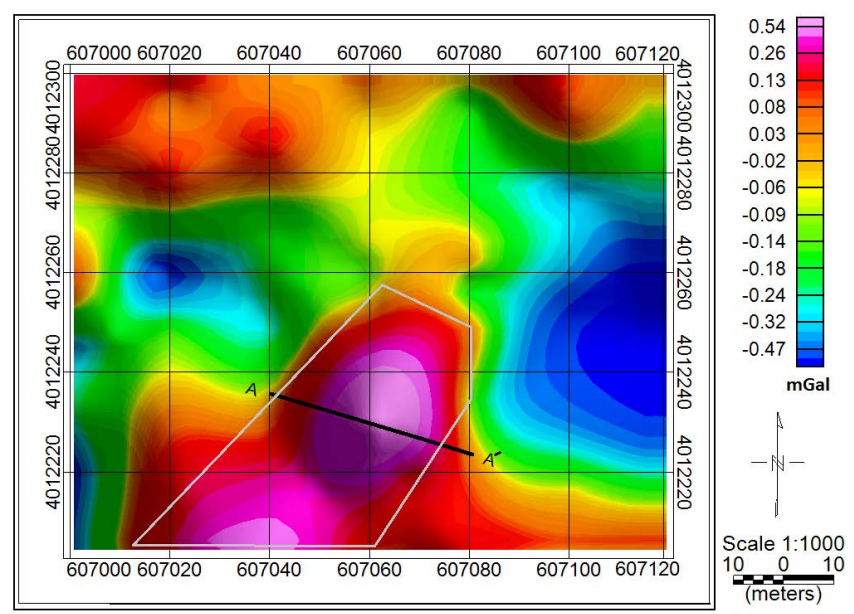

Fig. 22. The local gravity anomalies map. Gravity data from the chromite mass outlined in gray. Profile $A A^{\prime}$ has been shown on the positive gravity anomaly in a approximately W-E direction.

We applied the Marquardt inversion for the real gravity data where the causative mass shape was assumed as a sphere, an infinite horizontal cylinder and a semi-infinite vertical cylinder, separately. The initial values of the depth and radius parameters are given as $z=50 \mathrm{~m}$ and $R=15 \mathrm{~m}$ for the sphere model, $z=40 \mathrm{~m}$ and $R=25 \mathrm{~m}$ for the infinite horizontal cylinder model and $z=25 \mathrm{~m}$ and $R=15 \mathrm{~m}$ for the semi-infinite vertical cylinder model (Table 5). For each three supposed structure under consideration, the assigned values for misfit $(J)$, iteration and damping factor $(\lambda)$ are $0.001 \mathrm{mGal}, 100$ and 20 , respectively. The variability of each shape param- 
eter and misfit of the sphere, infinite horizontal cylinder and semi-infinite vertical cylinder geometry models against the iteration number during inversion process are shown in Figs. 23-25, respectively.

The performed iteration for the sphere, infinite horizontal cylinder and semi-infinite vertical cylinder configurations are 89,74 and 77 , respectively, before it was ceased, as in the end of these iteration numbers, the damping factor obtained a value greater than the allowable value. The depth and radius parameters and misfit abided constant after the 9th iteration in the case of the sphere shape, the 11th iteration in the case of the horizontal cylinder shape and the 6th iteration in the case of the vertical cylinder shape. The inverted structural parameters are given in Table 5 .

Table 5. Inferred numerical results from analyzing the real gravity data along the profile $A A^{\prime}$ cross-section and the gravity response of the assumed parameters for the each three structural shapes.

\begin{tabular}{|c|c|c|c|c|c|c|}
\hline Model & \multicolumn{2}{|c|}{ Sphere } & \multicolumn{2}{|c|}{ Horizontal cylinder } & \multicolumn{2}{|c|}{ Vertical cylinder } \\
\hline Parameter & $\operatorname{Depth}(\mathrm{m})$ & Radius (m) & Depth $(\mathrm{m})$ & Radius (m) & Depth (m) & Radius (m) \\
\hline Assumed & 50 & 15 & 40 & 25 & 25 & 15 \\
\hline Estimated & 24.7 & 19.8 & 8.1 & 11.6 & 7.4 & 11.7 \\
\hline Misfit (mGal) & \multicolumn{2}{|c|}{1.192} & \multicolumn{2}{|c|}{0.176} & \multicolumn{2}{|c|}{0.375} \\
\hline
\end{tabular}

The theoretical gravity anomaly along profile $A A^{\prime}$ and modeled gravity anomalies corresponding to the estimated parameters in the latest misfit function values are shown in Fig. 26. Since the least misfit function value

(a)

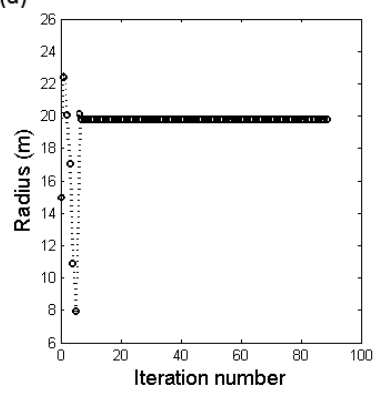

(b)

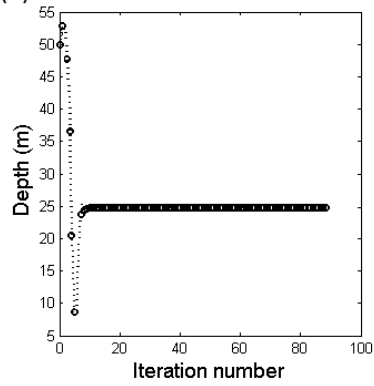

(c)

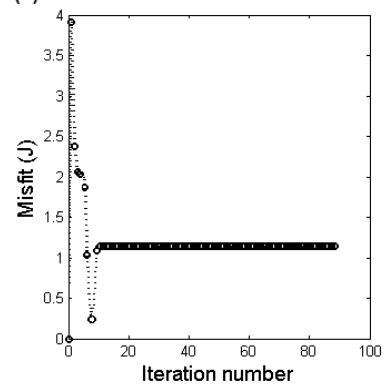

Fig. 23. Modifications of the structures parameters and misfit function versus iteration number based on assumed parameters for the sphere model as given in Table 5 . 
(a)

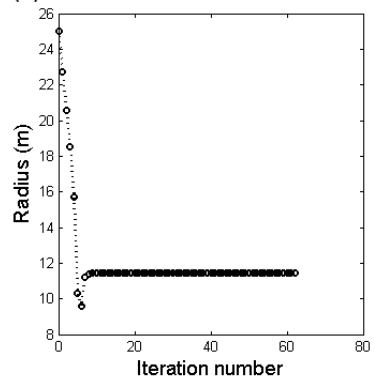

(b)

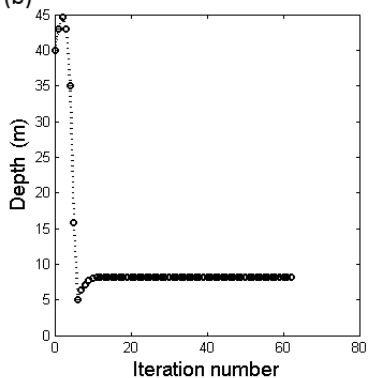

(c)

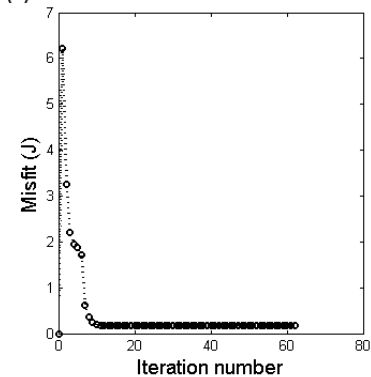

Fig. 24. Modifications of the structures parameters and misfit function versus iteration number based on assumed parameters for the horizontal cylinder model as given in Table 5 .

(a)

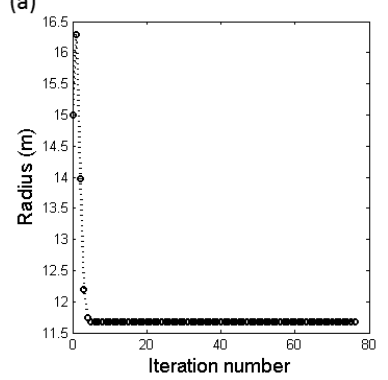

(b)

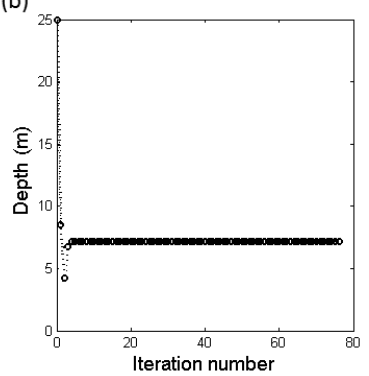

(c)

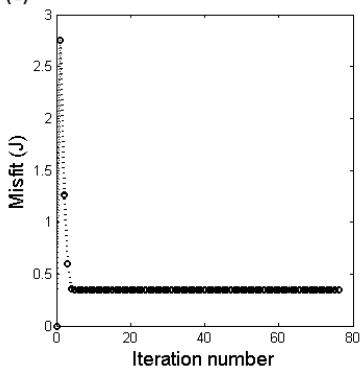

Fig. 25. Modifications of the structures parameters and misfit function versus iteration number based on assumed parameters for the vertical cylinder model as given in Table 5 .

(minimum error) indicate the best shape for the anomaly sources, with attention to Table 5, the horizontal cylinder model with a misfit value of $0.176 \mathrm{mGal}$, a depth of $8.1 \mathrm{~m}$ and a radius of $11.55 \mathrm{~m}$ must be the best form that can imagine for the anomaly causative body. But the computed structural parameter demonstrate a unrealistic structure, because if a subsurface source with the horizontal cylinder feature whose depth be $8.1 \mathrm{~m}$, the maximum value which the radius can possess, is equal the depth of the center of the model, while the inverted radius for the horizontal cylinder model is $11.6 \mathrm{~m}$. The average values of the depth and radius parameters estimated by the Marquardt inversion for the vertical cylinder model are $7.45 \mathrm{~m}$ and $11.7 \mathrm{~m}$ and for the sphere model are $24.8 \mathrm{~m}$ and $19.9 \mathrm{~m}$, respectively. There is a sharp discrepancy between the observed gravity (green curve in Fig. 26) and computed gravity response based on the inverted sphere model param- 


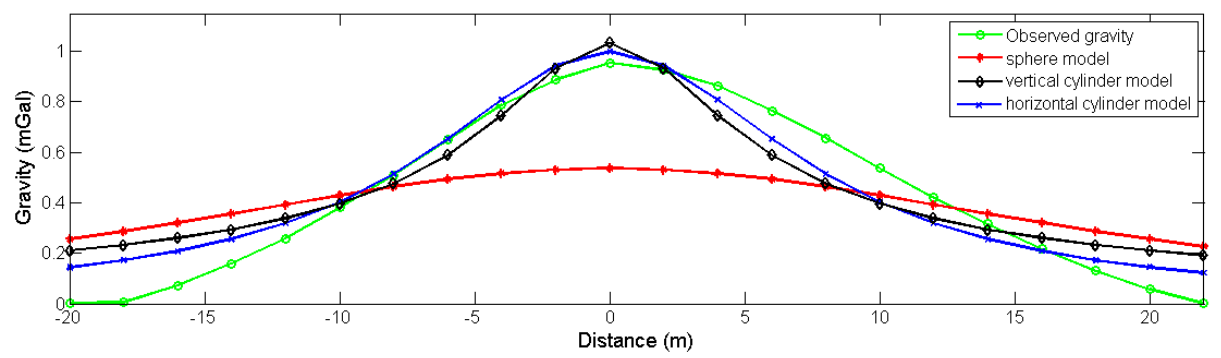

Fig. 26. The observed gravity along the profile $A A^{\prime}$ (green curve) and inverted gravity from the interpreted parameters for the assumed sphere model (red curve), horizontal cylinder model (blue curve) and vertical cylinder model (black curve).

eters (red curve in Fig. 26). As a result, the obtained value for the misfit, is larger than two other models and indicate the gravity anomaly source can't be sphere shape. Therefore, the best suitable geometric shape which can consider for the anomaly causative mass, i.e. chromite deposit, is the vertical cylinder form, because obtained misfit for the vertical cylinder model is smaller than one calculated for the sphere model.

The permanency and isotropy of the interpreted parameters from the real gravity data were investigated using different assumed values for the each three case of the models. The input and output values are summarized in Table 6. The estimated structural parameters illustrate a very slight differences that confirm the stability of the method.

The Euler deconvolution method is a common technique in potential fields study which is widely used for estimating the depth of the anomaly

Table 6. Inferred numerical results from analyzing the real gravity data along the profile $A A^{\prime}$ cross-section and the gravity response of the different assumed parameters for the each three structural shapes.

\begin{tabular}{|c|c|c|c|c|c|c|c|c|c|c|c|c|}
\hline Model & \multicolumn{4}{|c|}{ Sphere } & \multicolumn{4}{|c|}{ Horizontal cylinder } & \multicolumn{4}{|c|}{ Vertical cylinder } \\
\hline Parameter & $\begin{array}{c}\text { Depth } \\
(\mathrm{m})\end{array}$ & $\begin{array}{l}\text { Radiu } \\
\text { (m) }\end{array}$ & $\begin{array}{c}\text { Depth } \\
(\mathrm{m})\end{array}$ & $\begin{array}{l}\text { Radius } \\
(\mathrm{m})\end{array}$ & \begin{tabular}{|c|} 
Depth \\
$(\mathrm{m})$
\end{tabular} & $\begin{array}{l}\text { Radius } \\
(\mathrm{m})\end{array}$ & \begin{tabular}{|c|} 
Depth \\
$(\mathrm{m})$
\end{tabular} & $\begin{array}{l}\text { Radius } \\
\text { (m) }\end{array}$ & $\begin{array}{c}\text { Depth } \\
\text { (m) }\end{array}$ & $\begin{array}{l}\text { Radiu } \\
(\mathrm{m})\end{array}$ & $\begin{array}{c}\text { Depth } \\
(\mathrm{m})\end{array}$ & $\begin{array}{c}\text { Radius } \\
(\mathrm{m})\end{array}$ \\
\hline Assumed & 28 & 10 & 55 & 30 & 35 & 20 & 30 & 15 & 18 & 12 & 10 & 15 \\
\hline Estimated & 24.8 & 19.7 & 24.8 & 20.1 & 8.1 & 11.5 & 8.1 & 11.6 & 7.5 & 11.7 & 7.4 & 11.7 \\
\hline Misfit (mGal) & \multicolumn{2}{|c|}{1.191} & \multicolumn{2}{|c|}{1.194} & \multicolumn{2}{|c|}{0.175} & \multicolumn{2}{|c|}{0.176} & \multicolumn{2}{|c|}{0.376} & \multicolumn{2}{|c|}{0.375} \\
\hline Iteration & \multicolumn{2}{|c|}{95} & \multicolumn{2}{|c|}{85} & \multicolumn{2}{|c|}{71} & \multicolumn{2}{|c|}{64} & \multicolumn{2}{|c|}{67} & \multicolumn{2}{|c|}{53} \\
\hline
\end{tabular}


source (Thompson, 1982; Reid et al., 1990; Barbosa and Silva, 2011). In this study, for comparison the depth estimates from gravity data, we have employed the Euler method for calculating the depth of the chromite mineral mass by choosing a structure index of 1 and a window size of $5 \times 5$ points. Fig. 27 show the solutions obtained from Euler deconvolution as plotted on the residual gravity anomaly map. The Euler solutions located on the gravity anomaly present a depth between 5 to $10 \mathrm{~m}$ for the buried deposit.

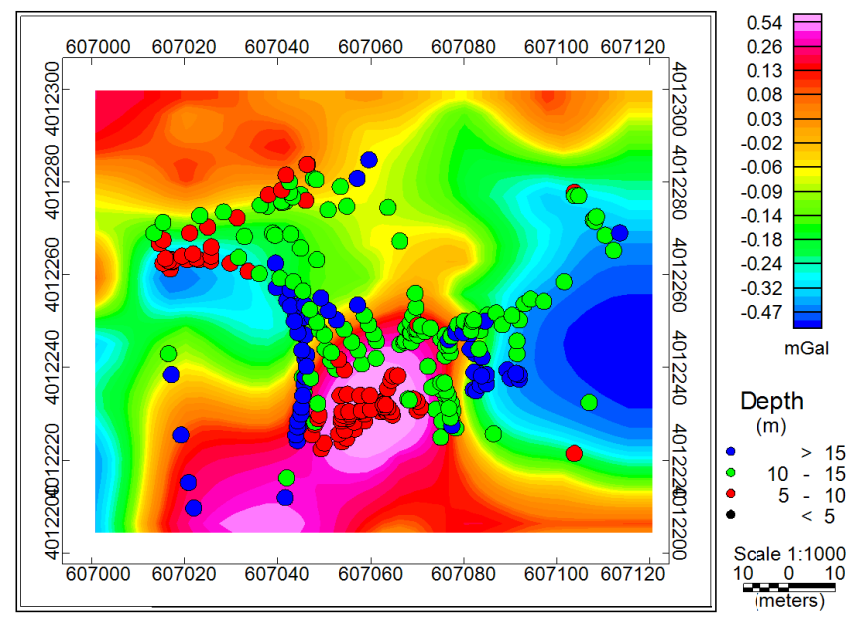

Fig. 27. The residual gravity anomalies overlaid by solutions of the 3D Euler method.

\section{Conclusions}

In this paper, we have introduced a optimization approach based on the Marquardt's algorithm for the inverse modeling of the residual gravity anomaly due to the simple geometric shapes, i.e. sphere, infinite horizontal cylinder and semi-infinite vertical cylinder. To check the constancy of the procedure and the convergency of the parameters attained from the Marquardt inversion, the free-noise and noise-impregnated theoretical gravity data related to the different initial models were used in each case and it was eventuated that the inversion yields almost the same solutions in all cases. Therefore, the stable and accurate solutions verify the reliability and applicability of the Marquardt's algorithm as a powerful and useful inverse modeling tools. 
The method was applied for estimating the structure parameters and determining the geometric shape using the gravity anomaly of a chromite deposit from Iran. The minimum misfit value was considered as a criterion for selecting the best mass shape, provided that the estimated parameters depict a acceptable structure naturally. The amount of misfit obtained for the assumed sphere models after 95 and 85 iterations is $1.191 \mathrm{mGal}$ and $1.194 \mathrm{mGal}$, for assumed horizontal cylinder models after 71 and 64 iterations is $0.175 \mathrm{mGal}$ and $0.176 \mathrm{mGal}$ and for assumed vertical cylinder models after 67 and 53 iterations is $0.376 \mathrm{mGal}$ and $0.375 \mathrm{mGal}$, respectively. Although the lowest estimated misfit is related to the horizontal cylinder model, but with attention to the inferred parameters for the horizontal cylinder models from the inversion, that is an average depth and radius of $8.1 \mathrm{~m}$ and $11.55 \mathrm{~m}$ respectively, these amounts do not demonstrate a subsurface body. The inverted gravity from the final interpreted parameters of this procedure for various assumed vertical cylinder models is very close to the real gravity along profile $A A^{\prime}$ cross-section. Therefore, it can be found that the anomaly causative mass shape is approximately the vertical cylinder form geometrically and depth and radius of the deposit are about $7.4 \mathrm{~m}$ and $11.7 \mathrm{~m}$. This evaluated depth has good conformity with the Euler solutions.

\section{References}

Abdelrahman E. M., Bayoumi A. I., Abdelhady Y. E., Gobashy M. M., El-Araby H. M., 1989: Gravity interpretation using correlation factors between successive leastsquares residual anomalies. Geophysics, 54, 12, 1614-1621, doi: 10.1190/1.1442 629.

Abdelrahman E. M., Bayoumi A. I., El-Araby H. M., 1991: A least-squares minimization approach to invert gravity data. Geophysics, 56, 1, 115-118, doi: 10.1190/1.1442 946.

Abdelrahman E. M., El-Araby T. M., 1993a: A least-squares minimization approach to depth determination from moving average residual gravity anomalies. Geophysics, 58, 12, 1779-1784, doi: 10.1190/1.1443392.

Abdelrahman E. M., El-Araby H. M., 1993b: Shape and depth solutions from gravity using correlation factors between successive least-squares residuals. Geophysics, 58, 12, 1785-1791, doi: 10.1190/1.1443393.

Al-Garni M. A., 2013: Inversion of residual gravity anomalies using neural network. Arab. J. Geosci., 6, 5, 1509-1516, doi: 10.1007/s12517-011-0452-y. 
Asfahani J., Tlas M., 2008: An automatic method of direct interpretation of residual gravity anomaly profiles due to spheres and cylinders. Pure Appl. Geophys., 165, 5, 981-994, doi: 10.1007/s00024-008-0333-9.

Barbosa V. C. F., Silva J. B. C., 2011: Reconstruction of geologic bodies in depth associated with a sedimentary basin using gravity and magnetic data. Geophys. Prospect., 59, 6, 1021-1034, doi: 10.1111/j.1365-2478.2011.00997.x.

Bowin C., Scheer E., Smith W., 1986: Depth estimates from ratios of gravity, geoid, and gravity gradient anomalies. Geophysics, 51, 1, 123-136, doi: 10.1190/1.1442025.

Chakravarthi V., Sundararajan N., 2004: Ridge-regression algorithm for gravity inversion of fault structures with variable density. Geophysics, 69, 6, 1394-1404, doi : 10.1190 /1. 1836814 .

Chakravarthi V., Sundararajan N., 2005: Gravity modeling of $2^{1 / 2}$-D sedimentary basins - a case of variable density contrast. Comput. Geosci., 31, 7, 820-827, doi : 10.1016 /j.cageo.2005.01.018.

Chakravarthi V., Sundararajan N., 2006: Gravity anomalies of 2.5-D multiple prismatic structures with variable density: A Marquardt inversion. Pure Appl. Geophys., 163, 1, 229-242, doi: 10.1007/s00024-005-0008-8.

Chakravarthi V., Sundararajan N., 2007: Marquardt optimization of gravity anomalies of anticlinal and synclinal structures with prescribed depth-dependent density. Geophys. Prospect., 55, 4, 571-587, doi: 10.1111/j.1365-2478.2007.00625.x.

Chakravarthi V., Sundararajan N., 2008: TODGINV-A code for optimization of gravity anomalies due to anticlinal and synclinal structures with parabolic density contrast. Comput. Geosci., 34, 8, 955-966, doi: 10.1016/j.cageo.2007.11.002.

Eshaghzadeh A., Kalantari R. A., 2015: Anticlinal Structure Modeling with Feed Forward Neural Networks for Residual Gravity Anomaly Profile. Proceedings of the 8th Congress of the Balkan Geophysical Society, 5-8 October 2015, Chania, Greece, doi : $10.3997 / 2214-4609.201414210$.

Eshaghzadeh A., Hajian A., 2018: 2D inverse modeling of residual gravity anomalies from Simple geometric shapes using Modular Feed-forward Neural Network. Ann. Geophys.-Italy, 61, 1, SE115, doi: 10.4401/ag-7540.

Essa K. S., 2007: A simple formula for shape and depth determination from residual gravity anomalies. Acta Geophys., 55, 2, 182-190, doi: 10.2478/s11600-007-0003-9.

Gupta O. P., 1983: A least-squares approach to depth determination from gravity data. Geophysics, 48, 3, 357-360. doi: 10.1190/1.1441473.

Hammer S., 1977: Graticule spacing versus depth discrimination in gravity interpretation. Geophysics, 42, 1, 60-65, doi: 10.1190/1.1440714.

GSI, 2019: Geological Survey \& Mineral Explorations of Iran, website, accessed 15 May 2019, https://www.gsi.ir/.

Lines L. R., Treitel S., 1984: A review of least-squares inversion and its application to geophysical problems. Geophys. Prosp., 32, 2, 159-186, doi: 10.1111/j.1365-2478. 1984.tb00726.x.

Marquardt D. W., 1963: An algorithm for least-squares estimation of nonlinear parameters. J. Soc. Indust. Appl. Math., 11, 2, 431-441, doi: 10.1137/0111030. 
McCowan D. W., Abdelrahman E. M., 1990: On "A least-squares approach to depth determination from gravity data" by O. P. Gupta. Geophysics, 55, 376-378, doi: 10. 1190/1.1442846.

Mohan N. L., Anandababu L., Rao S., 1986: Gravity interpretation using the Mellin transform. Geophysics, 51, 1, 114-122, doi: 10.1190/1.1442024.

Odegard M. E., Berg J. W., 1965: Gravity interpretation using the Fourier integral. Geophysics, 30, 3, 424-438, doi: 10.1190/1.1439598.

Osman O., Muhittin A. A., Ucan O. N., 2006: A new approach for residual gravity anomaly profile interpretations: Forced Neural Network (FNN). Ann. Geophys.Italy, 49, 6, 1201-1208, doi : 10.4401/ag-3099.

Osman O., Muhittin A. A., Ucan O. N., 2007: Forward modeling with Forced Neural Networks for gravity anomaly profile. Math. Geol., 39, 593-605, doi: 10.1007/s11004 -007-9114-8.

Reid A. B., Allsop J. M., Granser H., Millet A. J., Somerton I. W., 1990: Magnetic interpretation in three dimensions using Euler deconvolution. Geophysics, 55, 1, 80-91, doi: 10.1190/1.1442774.

Salem A., Ravat D., Johnson R., Ushijima K., 2001: Detection of buried steel drums from magnetic anomaly data using a supervised neural network. J. Environ. Eng. Geoph., 6, 3, 115-122, doi: 10.4133/JEEG6.3.115.

Saxov S., Nygaard K., 1953: Residual anomalies and depth estimation. Geophysics, 18, 4, 913-928, doi: 10.1190/1.1437945.

Sharma B., Geldart L. P., 1968: Analysis of gravity anomalies of two-dimensional faults using Fourier transforms. Geophys. Prosp., 16, 1, 77-93, doi : 10.1111/j.1365-2478 .1968.tb01961.x.

Shaw R. K., Agarwal N. P., 1990: The application of Walsh transforms to interpret gravity anomalies due to some simple geometrically shaped causative sources: A feasibility study. Geophysics, 55, 7, 843-850, doi: 10.1190/1.1442898.

Thompson D. T., 1982: EULDPH: A new technique for making computer assisted depth estimates from magnetic data. Geophysics, 47, 1, 31-37, doi: 10.1190/1.1441278. 